\title{
Human Amniotic Membrane Preparation, Preservation and Clinical Application Using Various Techniques for the Treatment of Ophthalmic Dysfunctions
}

Md. Arifuzzaman ${ }^{1 \#}$, Md. Liakat Hossain ${ }^{1 \#}$, Farzana Diba ${ }^{1}$, Ayesha Siddika $^{1}$, MH Adnan ${ }^{1}$, Naznin Akhtar ${ }^{1}$, Md. Zahid Hasan', S.M. Asaduzzaman ${ }^{1 *}$

1 Institute of Tissue Banking and Biomaterial Research, Atomic Energy Research Establishment (AERE), Savar, Dhaka-1349, Bangladesh

\#These two authors contributed equally.

*Corresponding Author:

Md. Liakat Hossain

Phone number: $+880-1731980316$

Fax: +887790034

E-mail: liakat88ju@gmail.com or liakat38ju@baec.gov.bd

Institute of Tissue Banking and Biomaterial Research, Atomic Energy Research

Establishment, Savar, Dhaka-1349, Bangladesh 


\begin{abstract}
The aim of this study is to emphasize on the clinical uses of amniotic membrane (AM) in multiple ocular disorders. AM possesses many properties including promotion of epithelialization, anti-fibrotic, anti-apoptotic, anti-angiogenic properties. Epithelial wound healing on the eye surface is promoted due to several epidermal and keratocyte growth factors as well as by its anti-inflammatory and anti-scarring effects due to interleukin-10, interleukin1 receptor antagonists and inhibition of transforming growth factor- beta (TGF- $\beta$ ) signal transduction by AM in the corneal and conjunctival fibroblasts respectively. It plays a crucial role by functioning as a substitute of basement membrane (BM) and as a temporary graft material. It is not only being used as an eye graft but also its extract can be used as an eye drop for corneal and external eye diseases. So its proper preparation, preservation and clinical application can bring a revolutionary change in the treatment of different ocular disorders.
\end{abstract}

Keywords: amniotic membrane; epithelialization; inflammation; ocular surface disorders; anti-fibrotic action, amniotic membrane eye drop, amniotic membrane graft transplantation. 


\section{Introduction}

The ocular surface is very sensitive and delicate structure which is very much vital for the proper functioning of the eye [1]. Ocular surface belongs to the corneal epithelium, conjunctival epithelium, and the lacrimal system [2]. Conjunctiva is the major support tissue of ocular surface [3], it provides an antimicrobial defense to ocular surface by secretion of different antimicrobial peptides [4]. Ocular surface diseases are one of the disorders of the surface of the cornea and the eyesight and the quality of life is severely affected by these disorders. Severe types of ocular surface disorders such as infection and chemical or thermal injuries can develop corneal scarring or stromal melts which leads to the depletion of limbal stem cells, which results in the impaired vision and corneal blindness [5]. Hence, ocular reconstructive surgery is needed for the reconstitution of anatomic and physiologic ocular surface to prevent recurrence of the causative ocular surface condition [6]. Now a day, AM is extensively employed for the treatment of burn injuries and different types of ophthalmic disorders. It is widely used in wound protection and pain reduction [7]. In 1910, Davis firstly reported that fetal membranes can be used of for skin transplantation [8] and De Roth first reported the application of fresh fetal membranes in the ocular surface in 1940 [9]. Furthermore, in 1946, Sorsby and in 1947 Simmons used chemically processed and dried AM for ocular chemical burns [10]. With the standardized technique, the Human amniotic membrane (HAM) has been used routinely in different ocular reconstructive surgery since 1995 [11]. AM is the innermost lining of fetal membrane contacting with the developing fetus and protects the fetus as a barrier from different types of infections and trauma [6]. It is separated from a single epithelium layer by a BM. It looks very thin, hard, transparent and can be easily separated from chorion [12]. It consists of a stromal matrix, a BM, nerve fibers, and lymphatic vessels [13]. Several extraordinary properties of AM have made it unique for ocular surface reconstruction which includes: modulation of inflammatory cascade by suppressing interleukins in epithelial cells [14], the release of basic fibroblast growth factors [15] and reduction of scar tissue formation by reducing polymorphonuclear infiltration [15]. Besides these properties, it has some antibacterial activities which lead the HAM for the treatment of ocular surface reconstruction [17]. After being separated HAM must be processed before use in ocular reconstructive surgery. There are several methods of processing and preservation of HAM, these are Heat dried AM, freeze-dried AM, Preservation of AM in cold glycerol 
and Cryopreserved or frozen AM [18]. Among these four types of preserved AM, cryopreserved AM manifests maximum biological properties compared to others and is designated as the best method of tissue processing for application in ocular surface disorders [19]. This method was first introduced by Kim and Tseng in 1995 [20]. The uniqueness of this method is that due to cryopreservation AM losses it is epithelial cells which ultimately results in the loss of immunogenicity [21]. The purpose of this review is to discuss the structure, characteristics, mechanism of action, processing method of the HAM. Moreover, the surgical techniques and the efficacy of amniotic membrane transplantation (AMT) in different types of ocular surface disorders are also evaluated in this review.

\section{Structure of HAM}

The fetal membrane is also known as chorioamniotic membrane. It consists of amnion and chorion which surrounds and provide protection to the developing fetus [22]. The chorion is vascular contacting with the uterine wall but amnion is avascular and is in contact with amniotic fluid. The thickness of AM varies from $0.02 \mathrm{~mm}$ to $0.5 \mathrm{~mm}$ and consists of three layers: the epithelial layer, the thick BM, and the avascular mesenchymal tissue [23]. Generally, AM contains no blood vessels and nerves its required nutrients are directly supplied by diffusion [24] and energy is derived from the anaerobic glycolytic pathway due to a limited oxygen supply [25]. The innermost layer is called amniotic epithelium. It is constituted by a monolayer of cuboidal epithelial cells and have microvilli at their apical surface and have intro- and transcellular functions [26]. Amniotic epithelial cells consist of a large irregular nucleus and many intracytoplasmic organelles [22]. Moreover, they express different types of epidermal marker e.g. glycoprotein cancer antigen 125 (CA125), Oxytocin receptor etc [27]. The BM is composed of type-IV, V, and VII collagen [28] and some molecules which play an efficient role to maintain structural integrity such as actin, $\alpha$-actinin, laminin, vimentin etc [29]. The outer layer of the AM also called zona spongiosa due to its abundance of proteoglycans and glycoproteins consists of mesenchymal fibroblast-like cells which creates a spongy appearance in histological preparations [30]. 


\section{Source of HAM}

In developing countries, amniotic membrane is generally cheap and freely available because the donor consent is readily available with less legislative considerations [31]. Generally, donors of amniotic membranes are pregnant mothers those delivered live baby through elective cesarean or vaginal section. But in this case, the maternal donor should undergo several types of serological tests due to the risk of several types of communicable diseases such as human immunodeficiency viruses, hepatitis B and C viruses, syphilis, herpes etc. It is better to repeat all serological tests in seronegative donor 6 months later of the previous test which helps to identify any types of infections of communicable diseases. AM collected from elective cesarean section is better than normal vaginal delivery because AM collected from normal vaginal delivery may be contaminated by various bacteria, vaginal flora, chlamydia etc. Moreover, there is a risk of stretching of the membrane during labor and delivery [32].

\section{HAM Processing and Preservation for Ocular Surgery}

$\mathrm{AM}$ is processed in a sterile condition. Placenta and fetal membranes which are collected from donors must be placed in a sterile organ bag and immediately transferred to the processing unit at $4{ }^{\circ} \mathrm{C}$. The whole processing procedure must be performed under a laminar flow hood. Under a laminar flow hood, the placenta is washed with sterile physiological saline to make it free from blood clots. After separation of the AM from the chorion by blunt dissection, it should be washed several times by using sterile physiological saline. Then, the AM is cut into small sizes $(4 \times 4 \mathrm{~cm})$ by using a sterile scalpel and again washed several times by sterile Phosphate Buffer Saline (PBS) containing antibiotic cocktail (penicillin $50 \mu \mathrm{g} / \mathrm{ml}$, streptomycin $50 \mu \mathrm{g} / \mathrm{ml}$, neomycin $100 \mu \mathrm{g} / \mathrm{ml}$ and amphotericin B $2.5 \mu \mathrm{g} / \mathrm{ml}$ ). Then, sterile nitrocellulose paper is taken and cut into small pieces $(4 \times 4 \mathrm{~cm})$. Under the aseptic condition, amniotic membranes should be flattened on to the nitrocellulose papers with the stromal surface and are placed in sterile falcon tubes containing Dulbecco's Modified Eagles Medium (DMEM) and glycerol at a ratio of $1: 1$. The falcon tubes are then stored at $-80{ }^{\circ} \mathrm{C}$ for cryopreservation. This method is called cryopreservation method and amniotic membranes which are preserved by this way called cryopreserved amniotic membrane. The cryopreserved amniotic membrane can be used effectively for more than a year. 


\section{Microbial Quality Check During Processing and Preservation Period}

In developing countries, most of the amniotic sacs are collected from normal vaginal deliveries are usually associated with different types of microbial flora from the labor room, the hospital personnel, and the donor [33]. Any type of microbial contamination can cause extreme danger since it is widely used in ocular surgery. So, before transplantation, it is essential to ensure amniotic allograft free from any types of microbial contamination. To confirm bioburden free amniotic allograft. Total Viable Bacterial Count (TVBC) and Total Viable Fungal Count (TVFC) of amniotic membranes should be determined after washing it with sterile PBS containing antibiotic cocktail. Moreover, during the preservation period at $-80^{\circ} \mathrm{C}$ TVBC and TVFC should also be determined 07 days, 14 days, 21 days \& 30 days' interval. If the TVBC and TVFC values of AMs found nil than those AMs will be designated microbiologically safe for transplantation.

\section{Mechanism of Action of AM}

The HAM has some unique properties which have made it susceptible to ocular surgery. Figure 1 shows the basic mechanism of action of AM in the healing process when it is transplanted in the ocular reconstructive surgery.

\subsection{Promotion of Epithelialization}

$\mathrm{AM}$ functions as BM which renders four main effects on the regeneration of corneal epithelium which includes enhancement of epithelial cell migration [34], augmentations of adhesion of basal epithelium cells [35], supports for epithelial differentiation [36] and epithelial apoptosis inhibition [37]. Moreover, the AM can generate the development and maintenance of progenitor epithelial cells in vivo [38]. It also helps in enhancing cellular proliferation and calcium metabolism by producing by brain natriuretic peptide and corticotrophin-releasing hormone [39]. All of these actions of AM influences epithelial healing of the ocular surface.

\subsection{Antimicrobial Action}

Due to antimicrobial properties of the AM, there is a lower risk of bacterial infection [40]. AM manifests its antibacterial activity against severe pathogenic microorganisms such as Staphylococcus aureus, Escherichia coli, streptococci, Pseudomonas aeruginosa [41]. It diminishes bacterial load by acting as a barrier against bacterial infiltration by adhesion to the wound surface. Several types of antimicrobial factors 
present in amniotic fluid bactericidin, transferring, lysozyme etc. contributes antimicrobial activities of AM [39]. Moreover, the AM also promotes bacterial killing by releasing some immunomodulatory factors [42].

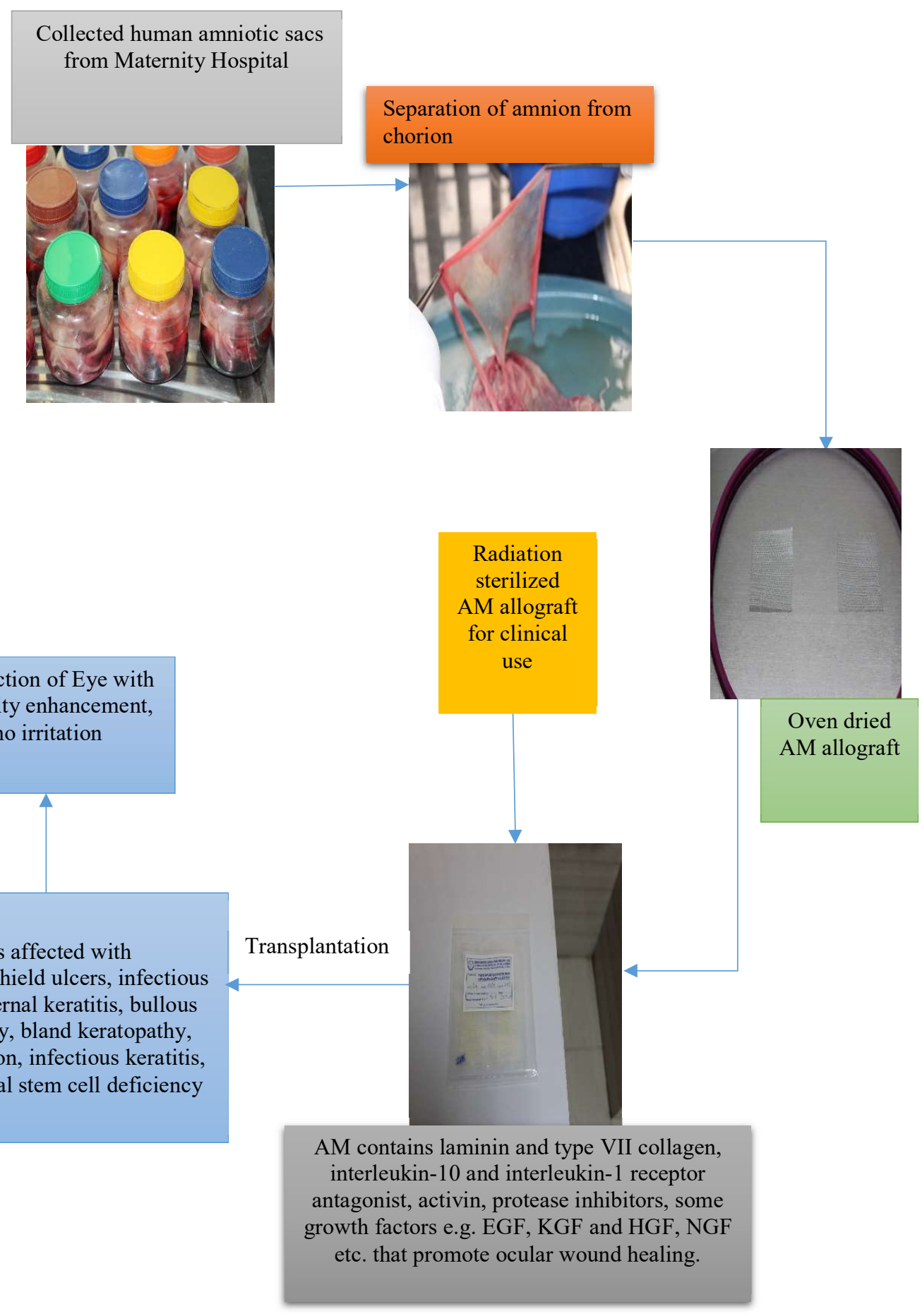

Reconstruction of Eye with visual acuity enhancement, and no irritation

Eyes affected with Pterygium, shield ulcers, infectious keratitis, vernal keratitis, bullous keratopathy, bland keratopathy, symblepharon, infectious keratitis, partial limbal stem cell deficiency

Figure 1. Mechanism of action of AM in the healing process of ocular reconstructive surgery. 


\subsection{Prevention of Fibrosis}

Fibroblasts are naturally responsible for scar formation. Transforming growth factorbeta (TGF- $\beta$ ) is responsible for the activation of fibroblasts. In the stromal matrix of $\mathrm{AM}$, there is an important constituent called fetal hyaluronic acid which suppresses TGF- $\beta$ signaling. Due to suppression of TGF- $\beta$ signaling proliferation of corneal, limbal, conjunctival fibroblasts and differentiation of fibroblasts into myofibroblast are inhibited. As a result, the formation of the scar after ocular surface reconstruction is significantly reduced [43].

\subsection{Anti-inflammatory Action}

AM shows its anti-inflammatory action due to the presence of mesenchymal cells that reduce the expression of pro-inflammatory cytokines e.g. interferon and tumor necrosis factor-alpha (TNF- $\alpha$ ), that enhances the anti-inflammatory cytokines secretion such as interleukin-4 (IL-4), IL-10, and IL-1 $\alpha$ [44]. In another way, amniotic membrane manifests its anti-inflammatory actions by the entrapment of inflammatory cells and undergo apoptosis in the matrix of the AM [45].

\subsection{Anti-angiogenic and Anti-Adhesive Actions}

HAM shows anti-angiogenic actions. Generally, it is avascular and it prevents the migration of Vascular Endothelial Growth Factor (VEGF) which leads the underlying cornea to receive AMs anti-angiogenic properties [46]. The anti-angiogenic action of $\mathrm{AM}$ is also rendered by the secretion of several anti-angiogenic factors such as thrombospondin-1, endostatin and Tissue inhibitor of metalloproteinase 1-4 (TIMP 14) [47]. Moreover, the AM also manifests its anti-angiogenic action by the expression of Pigment-epithelium derived factor (PEDF) [48]. On the other hand, preservation of human amniotic membrane at $-80{ }^{\circ} \mathrm{C}$ reveals the presence of Epidermal growth factor (EGF), Transforming growth factor- alpha (TGF - $\alpha$ ), keratinocyte growth factor (KGF), hepatocyte growth factor (HGF), basic fibroblast growth factor (b-FGF), Transforming growth factor - beta 1 (TGF- $\left.\beta_{1}\right)$., Transforming growth factor - beta 2 (TGF- $\beta_{2}$ ). Moreover, the basal membrane facilitates the migration of epithelial cells, reinforces the adhesion of basal epithelial cells and may promote the differentiation of epithelial cells [49].

\subsection{Pro-apoptotic Actions}

AM releases some substances which act as pro-apoptotic agents and can accelerate apoptosis of polymorphonuclear neutrophils [50]. It promotes the apoptosis of 
interferon- $\gamma$ activated macrophages that is not directly mediated by nitric oxide (NO) and tumor necrosis factor alpha (TNF- $\alpha$ ). However, this effect is commonly caused by the interruption of survival pathways mediated by both nuclear factor $\kappa \mathrm{B}(\mathrm{NF}-\kappa \mathrm{B})$ and Akt-forkhead transcription factor (Akt-FKHR) [22].

\subsection{Some Other Actions of AM}

AM-derived cells show pluripotency [51]. The expression of various stem cell markers e.g. octamer-binding transcription factor-4 (OCT-4), hepatocyte nuclear factor $3 \beta$ (HNF-3 $\beta$ ), Nanog and nestin reflects that amniotic cells possess the strong pluripotent potential to differentiate [52]. Moreover, different types of hepatic genes such as albumin, glutamine synthetase, carbamoyl phosphate synthetase I etc. are expressed in amniotic epithelial cells [22]. Besides the expression of hepatic genes different types of genes related to chondrocytes such as SOX, neuronal cells e.g. acetylcholine, catecholamines, dopamine neurotrophic factors are also expressed in amniotic epithelial cells [53]. The amniotic membrane consists of a cysteine proteinase inhibitor cystatin which performs an antiviral action [54]. Amniotic membranes are not tumorigenic and no tumorigenicity is not observed yet in humans who receive transplants of amniotic cells [55]. Moreover, Epithelial cells of AM do not express major histocompatibility antigens such as human leukocyte antigen (HLA) A, B or DR [56]. Hence, there is no risk of immunological rejection after its transplantation The amniotic membrane also has the unique property to reduce pain during the surgical procedure. It inhibits wound surface dehydration, which stimulates wound healing process [57].

\section{AM extracts eye drops mechanism}

Recent research has shown that an eye drop combined with amniotic membrane extracts and umbilical cord blood is more effective than AM [58]. Figure 2 shows the possible mechanism of amniotic membrane extract eye drops in corneal wound healing and regeneration. 


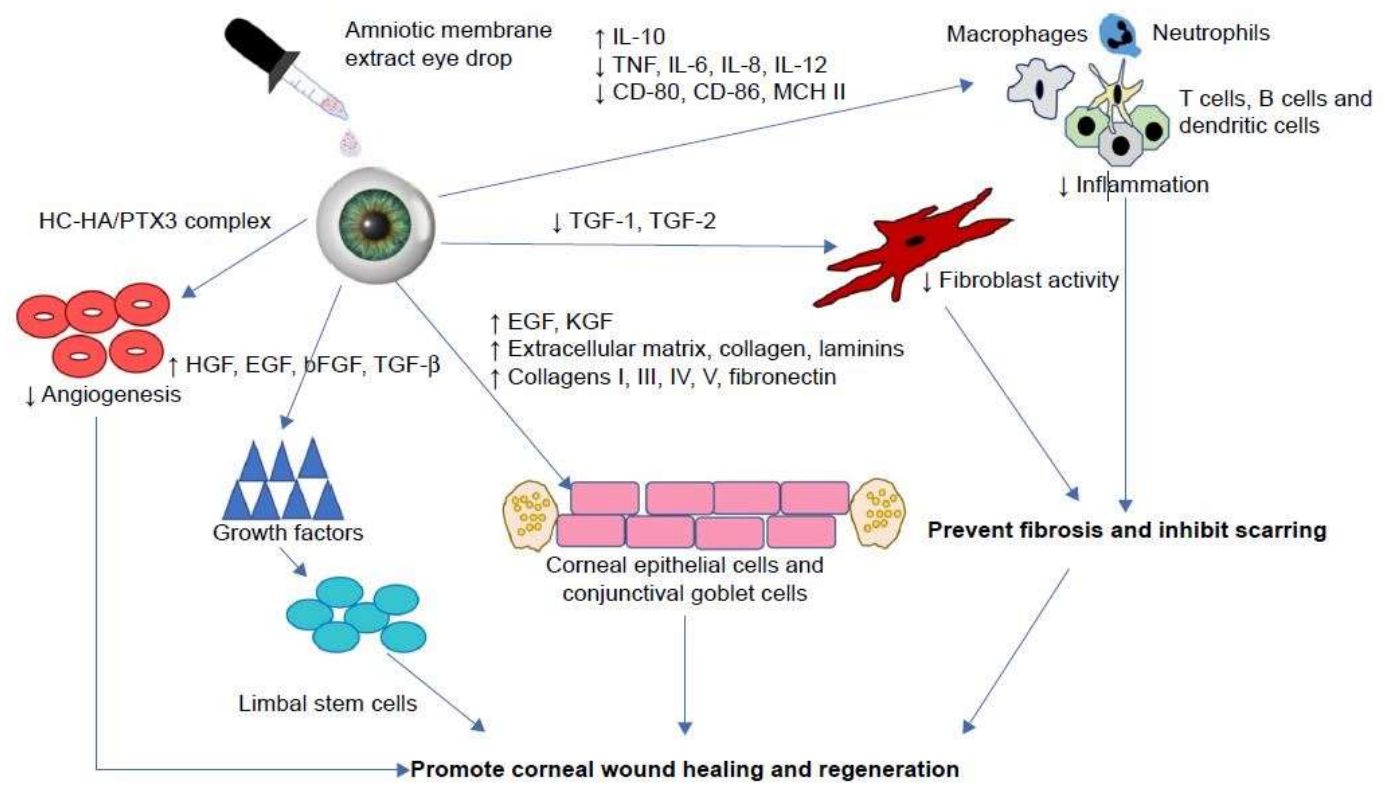

Figure 2. Proposed mechanism of action of amniotic extract eye drops role in promoting wound healing. Adapted from Murri MS et al with permission. [58].

\section{Why Cryopreserved AM is Best for Ocular Reconstructive Surgery}

Recently, ophthalmologists prefer to use the cryopreserved AM to treat ocular surface disorders because of its maximum biological effectiveness and lower risk of graft rejection. Due to preserve at "cryo" condition, amniotic epithelial cells are damaged and tissue losses its immunogenicity which ultimately mitigates the chance of graft rejection. ${ }^{33}$ Damaged epithelial cells function as a source of nutrients for the growth of conjunctival and corneal epithelial cells [59]. Moreover, during processing pathogen reduction is achieved by decontamination with an antibiotic cocktail. On the other hand, histochemical analysis of cryopreserved AM detected the presence of laminin 5 in the BM which is essential to activate migration and adhesion of corneal epithelium [20]. The cryopreserved AM has already been proved effective to prevent postoperative muscle adhesions. Cryopreservation maintains the original architecture of the AM extracellular matrix and the activity of key biological signals e.g. high molecular weight hyaluronic acid, pentraxin 3 etc. But, other types of preserved amniotic allograft (e.g. freeze dried, air dried) are completely lacked these vital components. Moreover, different types of intrinsic neurotropic substances have made it an excellent substrate for ocular reconstructive surgery. 


\section{AM transplantation techniques}

\subsection{Surgical Techniques}

On the basis of the ophthalmic indications, there are three different surgical techniques by which AM can be implanted on to the ocular surface. These are: graft or inlay technique, patch or overlay technique and combined or multilayer technique [59]. In the case of the cryopreserved AM, it is necessary to keep it at room temperature for at least 10 minutes before use [60]. In ocular surgery, the AM must be stitched to the ocular surface with the epithelial side up and the stromal side in direct contact with the eye. So, proper determination of both epithelial side and stromal side of the AM is compulsory during the processing period. The existence of vitreous-like strands those can be picked up by fine sterile forces clearly indicates the stromal side of the AM. During processing, the AM must be mounted on nitrocellulose filter paper with the epithelial side up and stromal side in direct contact with the paper. The description of these three surgical techniques are given below:

\subsection{Graft or Inlay Technique}

In graft or inlay technique, AM is administered as the permanent BM substitute that helps to grow epithelial cells acting as a scaffold. This technique is applied to persistent epithelial defects, corneal ulceration, and conjunctival tumors. In this technique, AM is generally sutured to the cornea using 10-0 sutures so that the nearby epithelial cells can shift on to the AM and the wound starts to improve [37]. After that, 1-2 mm of host corneal epithelium is removed surgically which confirms that the regenerating epithelium grows over the BM and therefore AM stroma is merged into the host tissue. The AM is stretched on to the ocular surface with the epithelial side up due to the excellent performance of the BM of the amnion as a substrate for the growth of progenitor epithelial cells [57]. If the underlying defect is very deep e.g. corneal ulceration multiple layers of AM can be applied in that case.

\subsection{Patch or Overlay Technique}

In patch or overlay technique, the AM is provisionally placed on the ocular surface as a "biological bandage" to save the fragile epithelium from frictions created by the movement of the eyelid. Here, the AMs stretch on to the ocular surface with the epithelial side up or stromal side up so that the epithelium can grow under the membrane which generally performs as "biological bandage". Then, it sutures on the ocular surface using 10-0 nylon suture and it must be applied on the ocular surface in the surface by keeping it larger than the defect. The main difference between inlay 
technique and overlay technique is that in overlay technique the AM become disassociated from the ocular surface after a certain time (generally one or two weeks) but in case of inlay technique but in inlay technique, the AM fixed permanently. As AM lasts only for a certain time in overlay technique, the anti-inflammatory action also limited which results delayed wound healing.

\subsection{Combined or Multilayer Technique}

In this technique, multiple layers are used where the smaller inner layer acts as a graft and larger outer layer acts as a patch. This technique is also called the combination of inlay technique and overlay technique and is generally applied for the treatment of deep corneal ulceration. The success rate of this technique is generally very high [61].

\subsection{ProKera - a Sutureless AM Graft}

Surgically suture is referred to a stitch which is used by surgeons to hold the tissue together. Limitations of sutures include prolonged surgical time, postoperative complications, and risk of inflammation. In 2003, U.S Food and Drug Administration (FDA) approved a cryopreserved AM which is clipped to a dual polycarbonate ring system referred to as ProKera. In the stromal side, it acts as a biological bandage in contact with the cornea. The polycarbonate ring has an inner diameter of $16 \mathrm{~mm}$ and an outer diameter of $22 \mathrm{~mm}$. It is then placed in the eye as like as large contract lens. However, ProKera device is an easier, less time consuming and economical procedure than other surgical techniques of the AM [42]. However, on the basis of the thickness ProKera amniotic membrane graft can be classified into three classes. These are ProKera ( $\sim 100 \mu \mathrm{m}$ thick), ProKera and ProKera plus ( $\sim 200 \mu \mathrm{m}$ thick). ProKera slim is generally effective for moderate indications e.g. recurrent corneal erosion, ProKera is effective for both mild and moderate indications and ProKera plus is effective for severe injuries e.g. chemical ocular burns.

\section{Clinical Significances of HAM in Different Ophthalmic Diseases}

Human AMTs have already been proved as a dynamic method for the treatment of the various ophthalmic disorder, especially for ocular surface disorders. And, its uses in different ophthalmic indications are increasing day by day. Different types of ocular surface disorders where cryopreserved amniotic membranes are extensively used include pterygium, shield ulcers, infectious keratitis, vernal keratitis, bullous keratopathy, bland keratopathy, symblepharon, infectious keratitis, partial limbal stem cell deficiency etc. Moreover, the cryopreserved AM has also been proved very 
effective for the treatment of different types of ocular burns. The clinical impact of the cryopreserved AM for the treatment of these disorders are highlighted below:

\subsection{Pterygium}

Pterygium is a very familiar disorder of ocular surface which is characterized by the benign growth of conjunctiva from the nasal side of the sclera. If untreated pterygium leads to ultimate vision loss. At present, AMT has been extensively used for the elimination of pterygium. It has a strong capacity for the suppression of fibroblast proliferation in normal conjunctiva as well as in Pterygium (Figure. 3) [1].
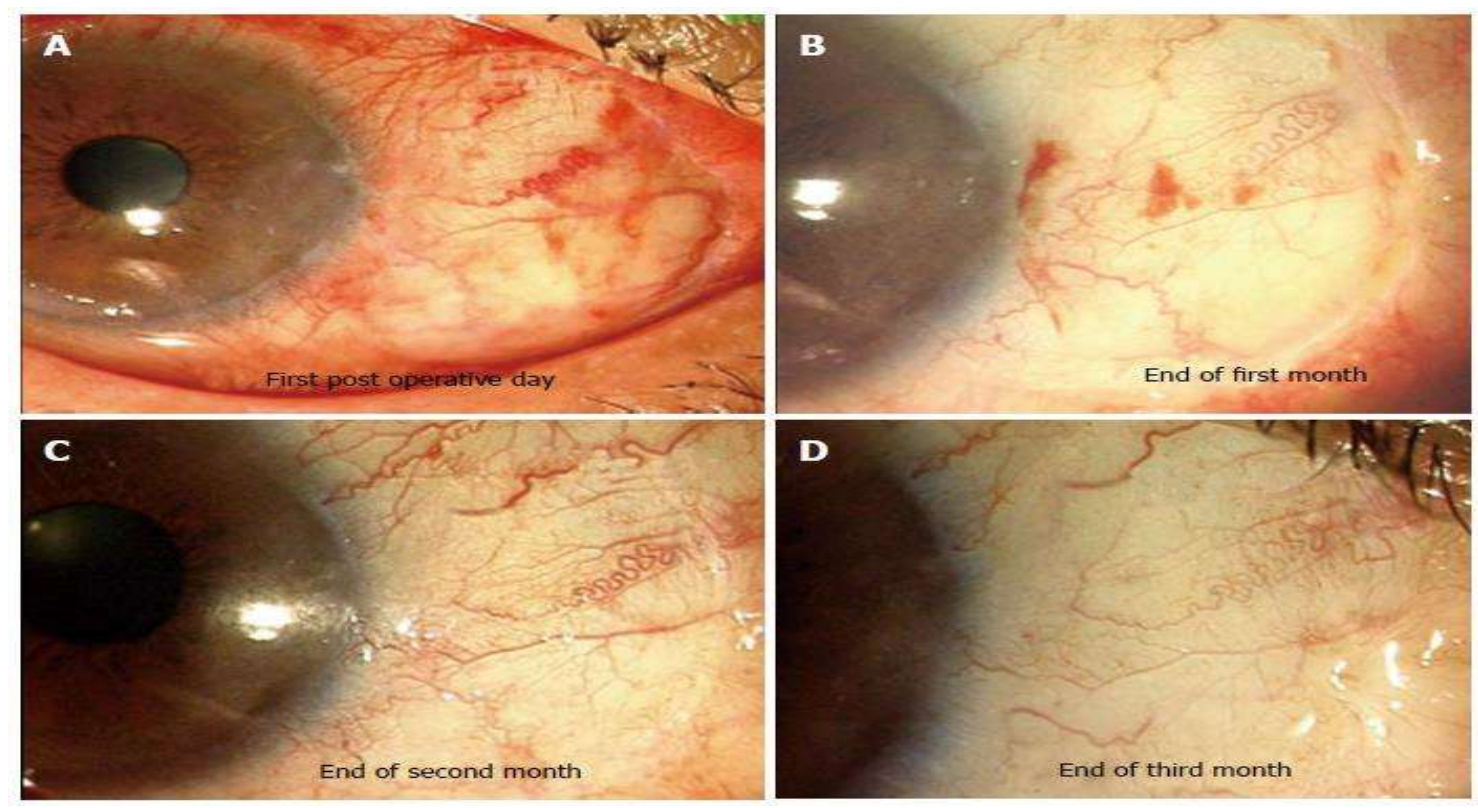

Figure 3. After excision of primary pterygium, AM was used to cover bare sclera. A-D shows the serial photographs of the appearance of AM graft. Serial photographs showing appearance of amniotic membrane graft. Excellent integration and cosmetic appearance was achieved after three months. Adapted from Malhotra $\mathrm{C}$ et al [1] with permission.

Previously, "bare sclera technique" was most widely used procedure for the removal of pterygium where pterygium head was removed from the corneal surface by simple excision [62]. But, this technique is associated with high recurrence problem which is due to the dysfunction of limbal stem cells and abnormal fibroblast proliferation [63]. It was seen that treatment of pterygium by AMT significantly reduce the recurrence rate which is $10.9 \%$ for primary pterygium and $37.5 \%$ for secondary pterygium. But, this rate is higher than the 
recurrence rates of conjunctival autograft. Recently, mitomycin-C (MMC) is used in combination with AMT is used for the removal of pterygium and this type of modification effectively reduces the recurrence rate which is $3 \%$ for primary pterygium and $9.5 \%$ for secondary pterygium and this recurrence rate is as like as the recurrence rate of conjunctival autograft [64,65]. Moreover, AMT also has been shown its effectiveness for the removal of pterygium from eyes with severe conjunctival defects [66]. A schematic diagram is given for showing the pterygium excision with AMT and conjunctival auto grafting (Figure. 4) [67].

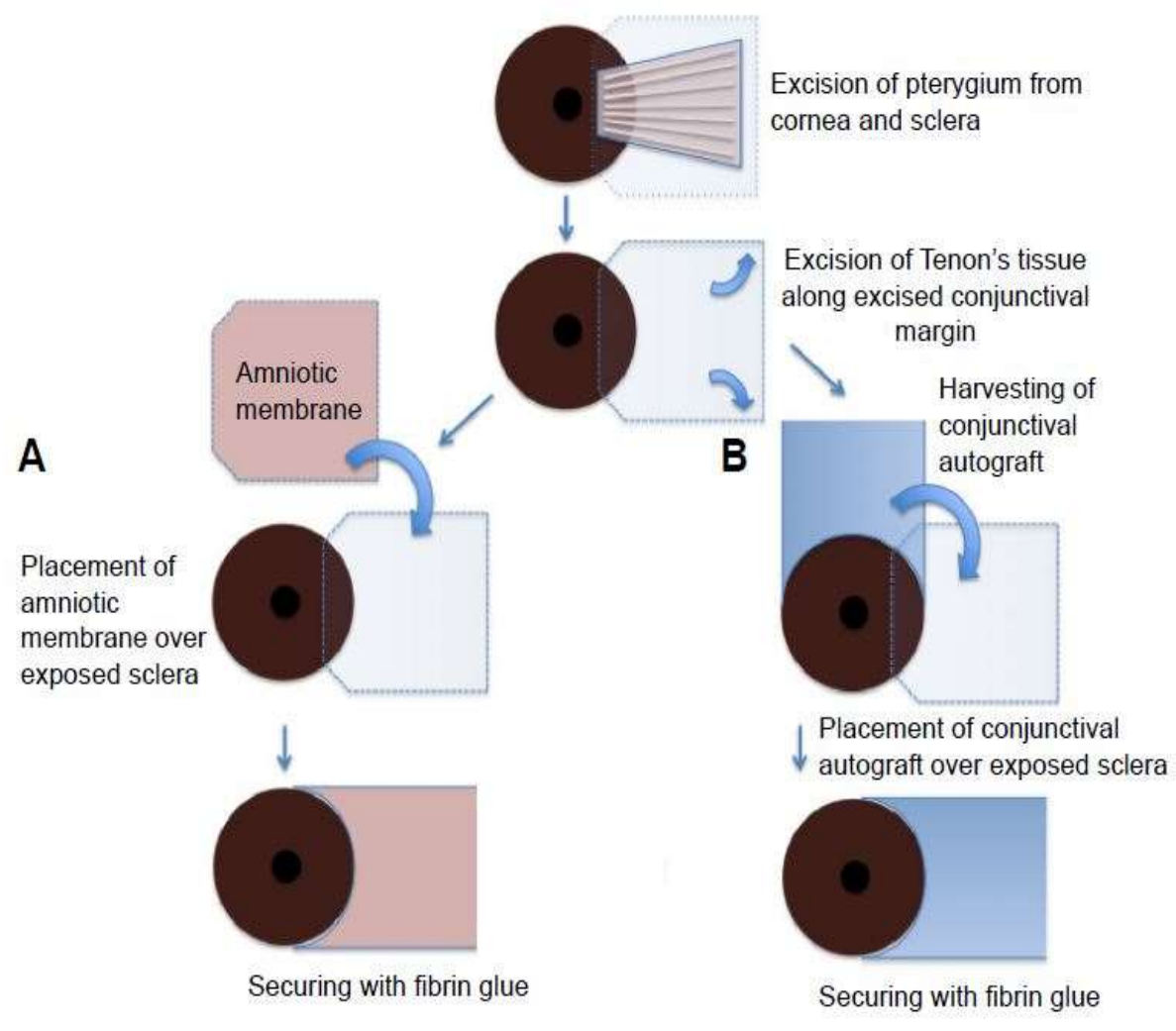

Figure 4. Schematic drawing of pterygium excision with AM transplantation (A) and conjunctival autografting (B). Adapted from Noureddin GS and Yeung SN [67] with permission.

\subsection{Shield Ulcers}

Shield ulcer is a rare type of corneal manifestation occurred in patients suffering from vernal keratoconjunctivitis which is an allergic inflammation of the ocular surface associated with tarsal and bulbar conjunctiva $[68,69]$. Different types of microbial keratitis, scarring or vascularization promotes shield ulcer in the eye affected with vernal keratoconjunctivitis [70]. However, this disease does not lead to blindness but 
visual impairment occurs in severe cases [71]. In case of shield ulcer, both medical and surgical treatments are prescribed on the basis of the severity of the disease. Generally, surgical intervention is mandatory for the treatment of grade II (ulcers with visual inflammatory debris in the base) and grade III shield ulcers (ulcers with elevated plaque). Common Surgical treatments of shield ulcer which have been prescribing for many years include mechanical debridement, superficial keratectomy and phototherapeutic keratectomy with or without contact lenses [72]. But some complications are seen during the postoperative period under existing surgical treatments. Incomplete removal of grade-III plaque results in relapse but complete removal of plaque results in stromal thinning. AMT has already been successfully proved to solve this problem. Recently a successful clinical investigation was done where AMT was used in 7 eyes of four patients suffering from grade II and grade III shield ulcers which result in healing of all eyes within 7-14 days and stromal defects were also filled up with multiple layers of AM [73]. Generally, multilayer technique is more favorable than monolayer technique for AMT in case of deep corneal ulcer [74]. Moreover, it was proved that the use of fibrin glue in association with AMT is better for the treatment of perforated ulcers than with AMT alone [75].

\subsection{Infectious Keratitis}

Keratitis is an inflammation of the cornea which is occurred in both children and adults. Generally different types of bacteria, fungus and parasites are responsible for keratitis in the human eye. Keratitis is characterized by pain, redness of the eye, light sensitivity, tearing and decreasing vision and if untreated for a long time it may lead to glaucoma, chronic inflammation of the cornea and finally loss of vision. However, AMT has been used for the treatment of bacterial, fungal and different types of parasitic keratitis [76]. But, sometimes AMT for the treatment of Acanthamoeba and fungal keratitis may be unsuccessful because fungal hyphae and Acanthamoeba cysts remain on the corneal stroma for a long time. So, it is better to prescribe AMT in case of infectious keratitis on the basis of cause and mode of infection.

\subsection{Bullous Keratopathy and Band Keratopathy}

Bullous keratopathy is characterized by the presence of corneal epithelial bullae which is formed due to the endothelial dysfunction. In this case, corneal endothelium fails to maintain the normal dehydrated state of the cornea which ultimately results in bullous keratopathy. However, treatments of bullous keratopathy include the use of topical dehydrating agents, intraocular pressure lowering agents, endothelial or penetrating 
keratoplasty etc. Recently, AMT has been used as a provisional measure before going to an effective treatment e.g. penetrating keratoplasty. In bullous keratopathy the objective of AMT to ensure longer pain-free periods among patients with poor visual potential where AMT is prescribed as a substitute of stromal puncture [77-79]. On the other hand, band keratopathy is a condition in which calcium deposits abnormally on the corneal surface. In this case, the deposition of calcium starts from temporal and nasal peripheries and then extend centrally and finally produce the continuous band. Band keratopathy is characterized by the irritation of the ocular surface and breakdown of epithelial surface. However, most effective treatment of band keratopathy is superficial keratectomy. AMT has already been proved very effective.

\subsection{Glaucoma}

Glaucoma is a kind of optic neuropathy which is characterized by the loss of retinal neurons and their axons. It may lead to permanent blindness if it remains untreated for a long time. Although trabeculectomy is widely used in a surgical procedure for the treatment of glaucoma [80], patients may suffer from postoperative operations after trabeculectomy because of healing in the episcleral surface inside the filtering bleb 8 . Use of AM in trabeculectomy enhances subconjunctival epithelial and fibroblast function promotes epithelial maturation and down-regulates fibrogenic TGF-b signaling and myofibroblast differentiation which leads to the prevention of healing subconjunctival space and promotes long-living blebs [12,20].

\subsection{Chemical Burns}

Chemical ocular burns may cause great damage to the eye. The severity of ocular damage generally depends on the type of the chemicals, $\mathrm{pH}$, the volume of exposed chemicals and the duration of the exposure. Most of the cases alkali burns are responsible for severe types of ocular damages [12]. Severe types of ocular damage caused by chemical burns are generally associated with severe ocular surface inflammation, deep stromal ischemia and total destruction of limbal stem cell. However, AMT in case of chemical ocular burns promote reduces inflammation and hinders the further damage to the limbal stem cells $[81,82]$.

\subsection{Conjunctival Tumors}

AMT has been successfully used for the reconstruction of ocular surface after removal of different types of benign and malignant tumors of the conjunctiva. The absence of donor site morbidity, superior postoperative cosmesis has made AMT effective for the treatment of conjunctival tumors [83]. Figure. 5 shows that AMT after excision of a 
large conjunctival tumor causes no sign of recurrence and no irritation following a cataract operation [84].
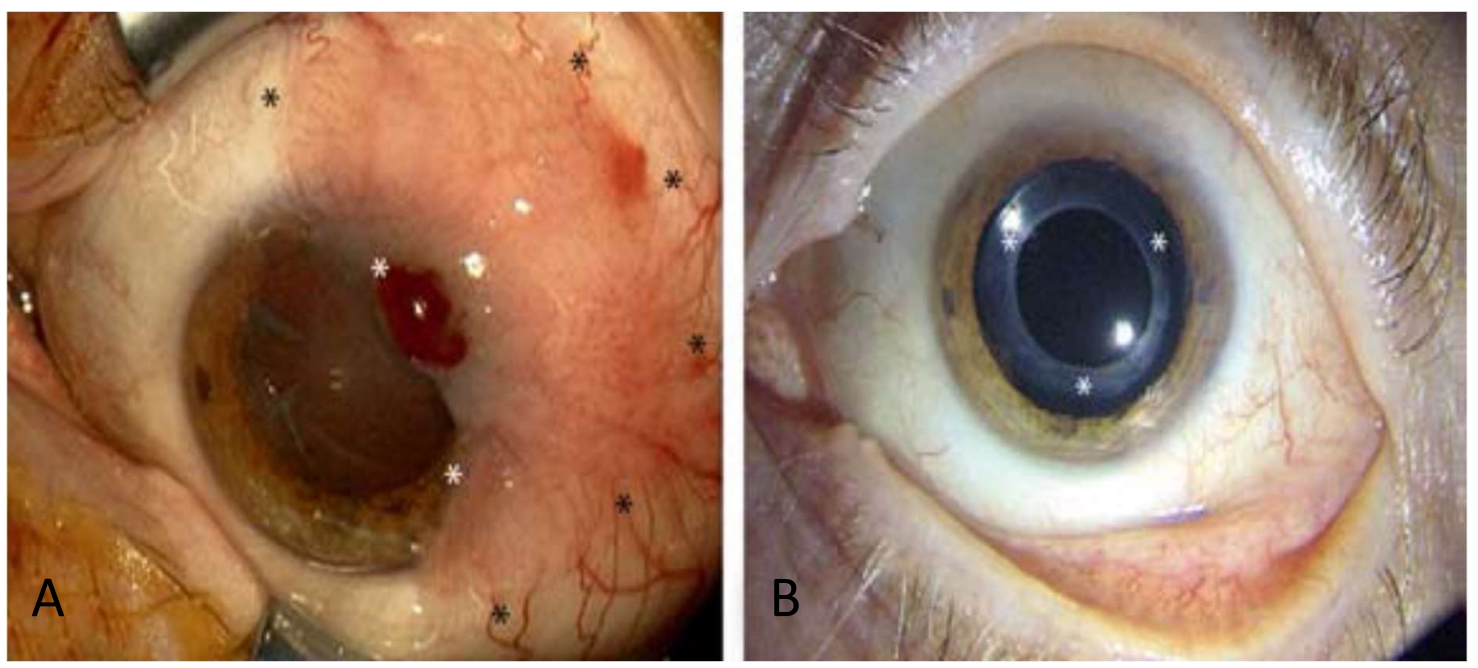

Figure 5. A defect covered after excision of conjunctival intraepithelial neoplasia: A) There was a large conjunctival tumor before surgery, (stars marked area). B) After 4 years of tumor excision and AM transplantation, there were no sign of recurrence and intraocular pseudophakia with no irritation following a cataract operation. Adapted from Meller et al. [84] with permission.

\section{Application of AM for Tissue Engineering of Limbal Epithelium}

Proper functions of corneal epithelium are necessary for clear vision. Limbal stem cell deficiency is an ocular surface disorder which is occurred due to the damage of limbal stem cells. In this disease, fibrovascular pannus tissues are formed on the corneal surface, glare sensitivity is enhanced, and finally, loss of vision is seen. However, surface reconstruction is the most effective treatment of this disease compared to limbus transplantation and it is gained by the restoration of limbal stem cell population [85]. Cultivation of limbal stem cells is done by tissue engineering. Besides, ex-vivo expansion of limbal epithelial cells can be cultivated on the AM in vitro and is transplanted on the diseased eyes. This technique is considered more effective than conventional autologous limbal transplantation. It was reported that about $83 \%$ of the treated patients gained increased visual activities by the successful application of this technique [86].

\section{Complications of AMT in Ocular Surface Reconstruction}

As AMT is widely recognized as an excellent procedure for the treatment of different types of severe ocular surface diseases, it has some limitations. One of the risks includes 
the transmission of various bacterial, viral and fungal infections from donor to the recipient if the collected membranes are not screened properly for different types of communicable diseases. Moreover, there may be problems during processing and storage of the AM. Sometimes the membranes may not be processed under sterile conditions. Moreover, it is important to know that AMT cannot be used to treat ocular disorders related to limbal or conjunctival stem cells, stromal ischemia etc. It cannot also be used for the structural reconstruction of the eye [87].

\section{Conclusion and future direction}

AMT has placed an important position for the treatment of ocular surface disorders. Its availability, mechanism of action such as the promotion of epithelialization, antifibrotic action, anti-angiogenic and pro-apoptotic actions etc. has made it unique for the treatment against deficiencies of ocular surface e.g. pterygium, shield ulcers, glaucoma, different types of ocular chemical burns etc. It has low immunogenicity, biocompatibility, elasticity, adequate mechanical properties and many essential growth factors. It contains laminin, proteoglycans, fibronectins and collagen types I, IV, V and VI. Laminin is involved in various biological activities such as cell growth, cell attachments and differentiation of cell types and collagens help to migrate adjacent autogenous connective tissue and epithelial cells over its surfaces. Moreover, fibronectin helps in tissue repair, cell migration, blood clotting and adhesion. The safety, no rejection phenomena and various surgical advantages of AM are vast. It has already been extensively used as a biological dressing in ophthalmic and plastic surgery. Besides, ophthalmologists are preferably using the cryopreserved AM in the treatment of ocular reconstructive surgery due to its lower risk of graft rejection and maximum biological effectiveness. It cannot be denied that AM (cryopreserved) is an ideal biological dressing material to treat various ocular disorders. Although it has some limitations, these are very simple and avoidable than its efficacy. However, AMT and AM extract eye drops might be a new frontier in the treatment of ocular reconstructive surgery and any corneal and external eye diseases especially for the people of poorer counties. The further development of this technique depends on further researches to eliminate its limitations. Besides this, huge amounts of clinical trials are necessary for the further development of AM extract eye drops and its transplantation which can open a new door in the field of ophthalmology. 


\section{Acknowledgments}

Not applicable

\section{Funding}

Not applicable

\section{Authors' contributions}

Md. Arifuzzaman carried out study design. literature citing, editing and manuscript writing. Md. Liakat Hossain helped to conduct literature citing and figure collection and manuscript writing. Farzana Diba, Naznin Akhtar, Ayesha Siddika, MH Adnan, contributed to literature citing and manuscript reading. Md. Zahid Hasan participated in helping to edit, revise and approve the final manuscript. S. M. Asaduzzaman supervised the writing of the manuscript and revised it critically for important intellectual content.

\section{Conflict of interest}

The authors declare that there is no conflict of interest regarding the publication of this paper. 


\section{References}

1. Malhotra C, Jain AK. Human amniotic membrane transplantation: Different modalities of its use in ophthalmology. World J Transplant. 2014, 4, 111-121.

2. Knop E, Knop N. Anatomy and immunology of the ocular surface. Chem Immunol Allergy. 2007, 92, 36-49.

3. Haynesa RJ, Tigheb PJ, Dua HS. Antimicrobial defensin peptides of the human ocular surface. Br J Ophthalmol. 1999, 83, 737-741.

4. Thylefors B, Negrel AD, Pararajasegaram R, Dadzie KY. Global data on blindness. Bull World Health Organ. 1995, 73, 115-121.

5. Nguyen P, Yiu SC. Ocular Surface Reconstruction: Recent Innovations, Surgical Candidate Selection and Postoperative Management. Expert Rev Ophthalmol. 2008, 3, $567-584$.

6. Ganatra MA. Amniotic Membrane in Surgery. J Pak Med Assoc. 2003, 53, 1-7.

7. Trelford JD, Trelford SM. The amnion in surgery, past and present. Am J Obstet Gynecol. 1979, 134, 833-845.

8. Rotth AD. Plastic repair of conjunctival defects with fetal membranes. Arch Ophthalmol. 1940, 23, 522-555.

9. Sorsby A, Symons HM. Amniotic membrane grafts in caustic burns of eye. $\mathrm{Br} \mathrm{J}$ Ophthalmol. 1946, 30, 337-345.

10. Adds PJ, Hunt C, Hartley S. Bacterial contamination of amniotic membrane. $\mathrm{Br} \mathrm{J}$ Ophthalmol. 2001, 85, 228-30.

11. Velez I, Parker WB, Siegel MA, Hernandez M. Cryopreserved Amniotic Membrane for Modulation of Periodontal Soft Tissue Healing: A Pilot Study. J Periodontol. 2010, $81,1797-1804$.

12. Dua HS, Gomes JA, King AJ, Maharajan VS. The amniotic membrane in ophthalmology. Surv Ophthalmol. 2004, 49, 51-77.

13. Solomon A, Rosenblatt M, Monroy D, Ji Z, Pflugfelder SC, Tseng SC. Suppression of interleukin 1alpha and interleukin 1beta in human limbal epithelial cells cultured on the amniotic membrane stromal matrix. Br J of Ophthalmology. 2001, 85, 444-449. 
14. Koizumi, N, Inatomi, T, Quantock A, Fullwood NJ, Dota A. Kinoshita S. Amniotic membrane as a substrate for cultivating limbal corneal epithelial cells for autologous transplantation in rabbits. Cornea. 2000, 19, 65-71.

15. Park WC, Tseng SCG. Modulation of acute inflammation and keratocyte death by suturing, blood, and amniotic membrane in PRK. Invest. Ophthalmol. Vis. Sci. 2000, 41, 2906-2914.

16. Muraine M, Descargues G, Franck O, et al. Amniotic membrane graft in ocular surface disease. Prospective study with 31 cases. J Fr Ophtalmol. 2001, 24, 798-812.

17. Baradaran-Rafii A, Hamid-Reza A, Arjmand B, MD; Mohammad-Ali J. Amniotic Membrane Transplantation. Iran J Ophthalmic Res. 2007, 2, 58-75.

18. Tseng SCG. Amniotic membrane transplantation for ocular surface reconstruction. Biosci Rep. 2002, 21, 481-489.

19. Kim JC, Tseng SCG. The effects on inhibition of corneal neovascularization after human amniotic membrane transplantation in severely damaged rabbit cornea. Korean J Ophthalmol. 1995, 9, 32-46.

20. Kim JC, Tseng SCG. Transplantation of preserved human amniotic membrane for surface reconstruction in severely damaged rabbit corneas. Cornea. 1995, 14, 437484.

21. http://eyewiki.aao.org/Amniotic_Membrane_Transplant.

22. Toda A, Okabe M, Yoshida T, Nikaido T The potential of amniotic membrane/amnion-derived cells for regeneration of various tissues. J Pharmacol Sci. $2007,105,215-228$.

23. Niknejad H, Peirovi H, Jorjani M, Ahmadiani A, Ghanavi J, Seifalian AM. Properties of the amniotic membrane for potential use in tissue engineering. European Cells and Materials. 2008, 15, 88-89.

24. Benedetti WL, Sala MA, Alvarez H. Histochemical demonstration of enzymes in the umbilical cord and membranes of human term pregnancy. Eur J Obstet Gynecol Reprod Biol. 1973, 3, 185-189.

25. Pollard S, Aye N, Symonds E. Scanning electron microscope appearances of normal human amnion and umbilical cord at term. Br J Obstet Gynaecol. 1976, 83, 470-477.

26. Sadler TW. Langmans medical embryology.12 $2^{\text {th }}$ ed. Slock, London, 2000. 
27. Fukuda K, Chikama T, Nakamura M, Nishida T. Differential distribution of subchains of the basement membrane components type IV collagen and laminin among the amniotic membrane, cornea and conunctiva. Cornea. 1999, 18, 73-79.

28. Wolf H, Desoye G. Immunohistochemical localization of glucose transporters and insulin receptors in human fetal membranes at term. Histochemistry. 1993, 100, 379385.

29. Parry S, Strauss J. Premature rupture of the fetal membranes. N Engl J Med. 1998, 338, 663-670.

30. Tseng SCG, Prabhasawat P, Lee SH. Amniotic membrane transplantation for conjunctival surface reconstruction. Am J Ophthalmol. 1997, 124, 765-774.

31. Ganatra MA, Bhura S. Management of skin graft donor site by irradiated amniotic membrane. Pakistan J Surg. 2003, 19, 82-85.

32. Mishanina E, Rogozinska E, Thatth T, Uddin-Khan R, Khan KS. and Meads C. Use of labour induction and risk of cesarean delivery: a systematic review and metaanalysis. CMAJ. 2014, 186, 665-673.

33. Shortt AJ, Secker GA, Rajan MS, et al. Ex vivo expansion and transplantation of limbal epithelial stem cells. Ophthalmol. 2008, 115, 1989-97.

34. Shimazaki J, Shinozaki N, Tsubota K. Transplantation of amniotic membrane and limbal autograft for patients with recurrent pterygium associated with symblepharon. Br J Ophthalmol. 1998, 82, 235-240.

35. Guo M, Grinnell F. Basement membrane and human epidermal differentiation in vitro. J Invest Dermatol. 1989, 93, 372-378.

36. Boudreau N, Sympson CJ, Werb Z. Suppression of ICE and apoptosis in mammary epithelial cells by extra cellular matrix. Science. 1995, 267, 891-893.

37. Grueterich M, Tseng SC. Human limbal progenitor cells expanded on intact amniotic membrane ex vivo. Arch Ophthalmol. 2002, 120, 783-790.

38. Cunningham FG, Gant NF, Leveno KJ. Williams obstetrics. 21st ed. London: Slock Inc; 2001.

39. Talmi YP, Sigler L, Inge E, Finkelstein Y, Zohar Y. Antibacterial properties of human amniotic membranes. Placenta.1991, 12, 285-8.

40. Chen HJ, Pires RTF, Tseng SCG. Amniotic membrane for sever neurotrophic ulcers. Br J Ophthalmol. 2000, 84, 826-833. 
41. Gudson J. A Bactericidin for bacillus subtilis in pregnancy. J Immunol. 1962, 88, 494-499.

42. Lee SB, Li DQ, Tan DT, Meller DC, Tseng SC. Suppression of TGF-B signaling in both normal conjunctival fibroblasts and pterygial body fibroblasts by amniotic membrane. Curr Eye Res. 2000, 20, 325-334.

43. Parolini O, Alviano F, Bagnara GP, et al. Concise review: isolation and characterization of cells from human term placenta: outcome of the first international workshop on placenta derived stem cells. Stem Cells. 2002, 26, 300-11.

44. Shimmura S, Shimazaki J, Ohashi Y, Tsubota K. Antiinflammatory effects of amniotic membrane transplantation in ocular surface disorders. Cornea. 2001, 20, 408-413.

45. Jiang A, Li C, Gao Y, et al. In vivo and in vitro inhibitory effect of amniotic extraction on neovascularization. Cornea. 2006, 25, S35-S40.

46. Hao Y, Ma DH, Hwang DG, Kim WS, Zhang F. Identification of antiangiogenic and antiinflammatory proteins in human amniotic membrane. Cornea. 2000, 19, 348-352.

47. Shao C. Suppression of corneal neovascularization by PEDF release from human amniotic membranes. Invest Ophthalmol Vis Sci. 2004, 45, 1758-1762.

48. Irfan Z. Qureshi, Fareeha A. and Wajid A. Khan. Technique for Processing and Preservation of Human Amniotic Membrane for Ocular Surface Reconstruction. World Academy of Science, Engineering and Technology. 2010, 45, 757-60.

49. Zhou S, Chen J, Feng J The effects of amniotic membrane on polymorphonuclear cells. Chin Med J. 2003, 116, 788-790.

50. Li W, He H, Kawakita T, Espana E, Tseng S. Amniotic membrane induces apoptosis of interferon-[gamma] activated macrophages in vitro. Exp Eye Res. 2006, 82, 282292.

51. Miki T, Lehmann T, Cai H, Stolz D, Strom S. Stem cell characteristics of amniotic epithelial cells. Stem Cells. 2005, 23, 1549- 1559.

52. Takashima S, Yasuo M, Sanzen N, et al. Characterization of laminin isoforms in human amnion. Tissue Cell. 2008, 40, 75-81.

53. Ni J, Abrahamson M, Zhang M. Cystatin E is a novel human cysteine proteinase inhibitor with structural resemblance to family 2 cystatins. J Biol Chem. 1997, 272, 10853-10858. 
54. Kamiya K, Wang M, Uchida S, et al. Topical application of culture supernatant from human amniotic epithelial cells suppresses inflammatory reactions in cornea. Exp Eye Res. 2005, 80, 671-679.

55. Adinolfi M, Akle CA, McColl I. Expression of HLA antigens, beta 2-microglobulin an enzyme by human amniotic epithelial cells. Nature. 1982, 295, 325-327.

56. Hajiiski $\mathrm{O}$ and Anatassov N. Amniotic membranes for temporary burn coverage. Ann Burn Fire Disasters. 1990, 9, 88-92.

57. Kruse FE, Rohrschneider K, Voelcker HE. Multilayer amniotic membrane transplantation for reconstruction of deep corneal ulcers. Ophthalmol. 1999, 106, 15041511.

58. Murri MS, Moshirfar M, Birdsong OC, Ronquillo YC, Ding Y, Hoopes PC. Amniotic membrane extract and eye drops: a review of literature and clinical application. Clin Ophthalmol 2018, 12, 1105-1112.

59. Kurpakus-Wheater M. Laminin-5 is a component of preserved amniotic membrane. Curr Eye Res. 2001, 22, 353-357.

60. Cauchi PA, Ang GS, Azuara-Blanco A, Burr JM: A systematic literature review of surgical interventions for limbal stem cell deficiency in humans. Am J Ophthalmol. 2008, 146, 251-9.

61. Dekaris I, Gabrić N, Mravicić I, et al. Multilayer vs. monolayer amniotic membrane transplantation for deep corneal ulcer treatment. Coll Antropol. 2001, 25, 23-8.

62. Song YW, Yu AH, Cai XJ. Effectiveness of amniotic membrane transplantation combined with mitomycin $\mathrm{C}$ in the treatment of pterygium: a meta-analysis. Int $J$ Opthalmol. 2010, 3, 352-355.

63. Prabhasawat P, Barton K, Burkett G. Comparison of conjunctival autografts, amniotic membrane grafts, and primary closure for pterygium excision. Ophthalmol. 1997, 104, 974-985.

64. Solomon A, Pires RT, Tseng SCG. Amniotic membrane transplantation after extensive removal of primary and recurrent pterygia. Ophthalmol. 2001, 108, 449460.

65. Ti SE, Tseng SCG. Management of primary and recurrent pterygium using amniotic membrane transplantation. Curr Opin Ophthalmol. 2002, 13, 204-212. 
66. Bonini S, Bonini S, Lambiase A, et al. Vernal keratoconjunctivitis revisited: A case series of 195 patients with long-term follow-up. Ophthalmol. 2000, 107, 1157-63.

67. Noureddin GS and Yeung SN. The use of dry amniotic membrane in pterygium surgery. Clin Ophthalmol. 2016, 10, 705-712.

68. Barney NP. Vernal and atopic keratoconjunctivitis. In: Krachmer JH, Mannis MJ, Holland EJ, editors. Cornea. 2nd ed. Philadelphia: Elsevier Mosby. 2005, 667-70.

69. Cameron JA. Shield ulcers and plaques of the cornea in vernal keratoconjunctivitis. Ophthalmol.1995, 102, 985-993.

70. Iqbal A, Jan S, Babar TF, Khan MD. Corneal complications of vernal catarrh. J Coll Physicians Surg Pak. 2003, 13, 394-97.

71. Cameron JA, Antonios SR, Badi IA. Excimer laser phototherapeutic keratectomy for shield ulcers and corneal plaques in vernal keratoconjunctivitis. J Refract Surg. 1995, 11, 31-35.

72. Sridhar MS, Sangwan VS, Bansal AK. Amniotic membrane transplantation in the management of shield ulcers of vernal keratoconjunctivitis. Ophthalmol. 2001, 108, 1218-1222.

73. Sangwan VS, Burman S, Tejwani S, Mahesh SP, Murthy R. Amniotic membrane transplantation: A review of current indications in the management of ophthalmic disorders. Indian J Ophthalmol. 2007, 55, 251-60.

74. Hick S, Demers PE, Brunette I, La C, Mabon M, Duchesne B. Amniotic membrane transplantation and fibrin glue in the management of corneal ulcers and perforations: A review of 33 cases. Cornea. 2005, 24, 369-77.

75. Lee-Wing MW. Amniotic membrane for repair of exposed hydroxyapatite orbital implant. Ophthal Plast Reconstr Surg. 2003, 19, 401-2.

76. Sheha H, Liang L, Li J, and Tseng SCG. Sutureless Amniotic Membrane Transplantation for Severe Bacterial Keratitis. Cornea. 2009,28, 1118-1123.

77. Pires RTE, Tseng SCG, Prabhasawat P. Amniotic membrane for symptomatic bullous keratopathy. Arch Ophthalmol. 1999, 117, 1291-1297.

78. Espana EM, Grueterich M, Sandoval H. Amniotic membrane transplantation for bullous keratopathy in eyes with poor visual potential. J Cataract Refract Surg. 2003, 29, 279-284.

79. Cairns JE. Trabeculectomy: Preliminary report of a new method. Am J Ophthalmol. $1968,66,673-9$. 
80. Molteno AC, Bosma NJ, Kittleson JM. Otago glaucoma surgery outcome study: longterm results of trabeculectomy - 1976 to 1995. Ophthalmol. 1999, 106, 1742-50.

81. Meller D, Pires RTF, Mack RJS. Amniotic membrane transplantation for acute chemical or thermal burns. Ophthalmol. 2000, 107, 980-990.

82. Ucakhan OO, Koklu G, Firal E. Non-preserved human amniotic membrane transp lantation in acute and chronic chemical eye injuries. Cornea. 2002, 21, 169-172.

83. Chen Z, Yan J, Yang H, et al. Amniotic membrane transplantation for conjunctival tumor. Yan Ke Xue Bao. 2003, 19, 165-7, 145.

84. Meller D, Pauklin M, Thomasen H, Westekemper H, Steuhl Klaus-Peter. Amniotic Membrane Transplantation in the Human Eye. Dtsch Arztebl Int. 2011, 108, 243-8.

85. Shortt AJ, Secker GA, Notara MD, et al. Transplantation of ex vivo cultured limbal epithelial stem cells: a review of techniques and clinical results. Surv Ophthalmol. 2007, 52, 483-502.

86. Burman S and Sangwan V. Cultivated limbal stem cell transplantation for ocular surface reconstruction. Clin Ophthalmol. 2008, 2, 489-502.

87. Thatte S. Amniotic membrane transplantation: An option for ocular surface disorders. Oman J Ophthalmol. 2011, 4, 67-72. 